\title{
Specialty crops and methyl bromide alternatives: taking stock after 7 years
}

Greg T. Browne

Research Plant Pathologist, Crops Pathology and Genetics Research Unit, USDA-ARS, Department of Plant Pathology, University of California, Davis

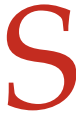
pecialty crop farms and nurseries in California, Oregon and Washington provide local and world markets with abundant fruit, nut and vegetable crops and planting stock. These operations thrive due to dedicated human investment and the availability of precious combinations of soil, climate and water resources. California alone

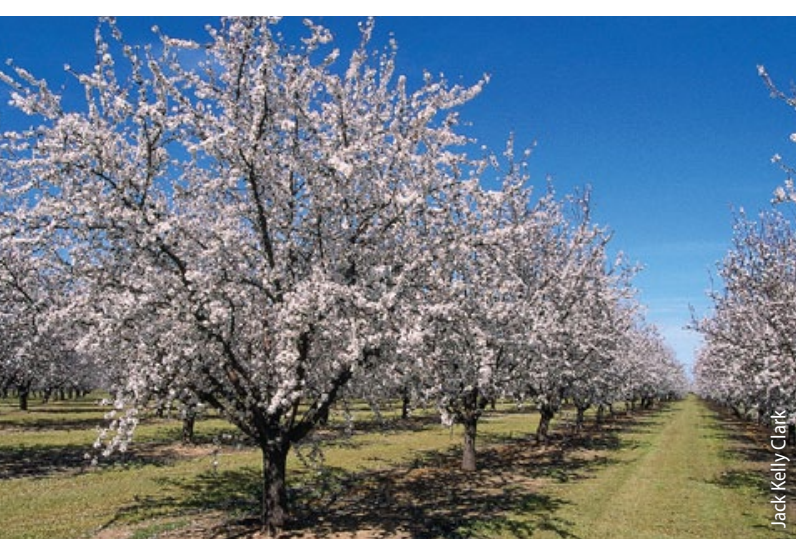

produces $99 \%$ of the

U.S. almond and walnut crops and $90 \%$ of the strawberry crop, and it supplies $99 \%$ or more of U.S. almond, raisin, table grape and walnut exports. Combined, California, Oregon and Washington account for roughly $32 \%$ of the U.S. floriculture crop value, $44 \%$ of the nursery crop value and $78 \%$ of the

Pest-free nursery stock and productive soils are vital to efficient use of land, water, energy and fertilizer resources for specialty crops such as almonds and grapes. Above, an almond orchard in bloom. fruit and nut crop value.

We all have a large stake in the availability of specialty crops. Research increasingly documents their benefits to our health. They are a livelihood, directly or indirectly, for many of us. As a society, we have contributed collectively to key infrastructures, such as water resource developments for irrigation and the land-grant college system with its associated teaching, research and extension functions. Indisputably, ample food production, including specialty fruits, nuts and vegetables, is a key measure of national and global security.

Yet specialty crop farming faces California Agriculture journal thanks the faculty chairs for this special collection: Greg Browne, Research Plant Pathologist, USDA Agricultural Research Service (USDA-ARS) and Department of Plant Pathology, UC Davis, and Brad Hanson, Cooperative Extension Specialist, University of California, Davis. We also thank the USDA-ARS Pacific Area-Wide Pest Management Program for Integrated Methyl Bromide Alternatives for helping defray the cost of this issue and the upcoming October-December 2013 edition. dollars of high-value specialty crops annually, was being phased out due to its contributions to ozone depletion in the stratosphere. Further, the immediate alternatives to methyl bromide, mainly a few other soil fumigants, were on "shaky ground" due to their own environmental challenges.

That year, the U.S. Department of Agriculture (USDA) launched the Pacific Area-Wide Pest Management Program for Integrated Methyl Bromide Alternatives (PAW-MBA). The program drew growers, nursery representatives, regulatory officials and scientists from California, Oregon and Washington to work together as a multidisciplinary team in response to the methyl bromide phase-out. Scientists from the USDA Agricultural Research Service, University of California, California Department of Pesticide Regulation, Oregon State University and Washington State University, along with public and private stakeholders, all were vital to development and implementation of the program.

The PAW-MBA sought to: 1) optimize available "next-best" fumigant alternatives to methyl bromide soil treatments and 2) foster development of non-fumigant alternatives. Specific needs of the targeted production systems (i.e., perennial and annual nursery crops, strawberries, almonds and stone fruits, walnuts and grapes) as well as over-arching environmental challenges (e.g., human health and safety; air, soil and water quality; efficient use of environmental resources) would be accommodated.

In the absence of methyl bromide, specific needs varied among the different production systems. Field nurseries needed alternatives to manage weeds (effective herbicides were not available) and nematodes (certification requires nursery stock to be nematode-free) over 1- to 2-year plant production cycles, and there was little flexibility for non-fumigant alternatives. In contrast, orchardists had less need to control weeds and more pressing needs to manage soilborne pathogen complexes (including but not limited to nematodes) over 15- to 30 -year production cycles. Compared to field nurseries, orchard, vineyard and strawberry producers had more flexibility to explore non-fumigant alternatives.

All of the PAW-MBA specialty crop systems shared the imperative to minimize non-target fumigant emissions to the atmosphere. Fumigants are hazardous, volatile, broad-spectrum biocides and are regulated accordingly at federal, state and county levels to keep bystanders safe and minimize 
